\title{
The reasons of dropout of sport in Hong Kong school athletes
}

\author{
Abdul-Rahman Hassan, ${ }^{1,2}$ Michael Huen Sum Lam, ${ }^{1,2}$ Susanna Ku, ${ }^{1}$ \\ William Ho Cheung Li, ${ }^{3}$ Ka Yiu Lee, ${ }^{1,2}$ Eva Ho, ${ }^{3}$ Stuart W. Flint, ${ }^{4}$ Anthony Siu Wo Wong ${ }^{1}$ \\ ${ }^{1}$ Vocational Training Council, Chai Wan, Hong Kong; ${ }^{2}$ Faculty of Health and Wellbeing, Sheffield \\ Hallam University, UK; ${ }^{3}$ School of Nursing, Li Ka Shing Faculty of Medicine, the University of \\ Hong Kong; ${ }^{4}$ Leeds Beckett University, UK
}

\begin{abstract}
Dropout of sport is an issue in sport and public health domains. The aim of this study was to identify the potential dropout reasons of school athletes and to examine if their perception of dropout was affected by the previous dropout experience. There were 50 subjects who were divided into two groups based on their previous dropout experience (Dropout Group=22, No Dropout Group=28). They filled a questionnaire about potential dropout reasons of the current sport. Coach and teammates were two predominated reasons of dropout; Influence of parent and training seemed to affect the termination of the sport to a lesser extent. Moreover, the perception of social value and lost focus were significantly different between two groups. Character of coach and teammates affect the engagement of training in school athletes. However, the parental influence had less influence than expected. Training intensity played little role as the dropout reason. Previous experience of dropout had an impact of potential dropout reasons on their current sport training.
\end{abstract}

\section{Introduction}

The health benefits of physical activity have been well-docu-

\author{
Correspondence: Michael Huen Sum Lam, School for Higher and \\ Professional Education, Hong Kong Institute of Vocational Education, \\ Chai Wan Campus, Hong Kong. \\ Tel.: +852.25952612 - Fax: +852.29765702 . \\ E-mail: michaelhslam@vtc.edu.hk \\ Key words: Dropout sports; Adolescent athlete; Coach; Teammate. \\ Contributions: the authors contributed equally. \\ Conflict of interest: the authors declare no potential conflict of interest. \\ Received for publication: 27 April 2017. \\ Accepted for publication: 28 April 2017. \\ This work is licensed under a Creative Commons Attribution- \\ NonCommercial 4.0 International License (CC BY-NC 4.0). \\ (C) Copyright A.-R. Hassan et al., 2017 \\ Licensee PAGEPress, Italy \\ Health Psychology Research 2017; 5:6766 \\ doi:10.4081/hpr.2017.6766
}

mented (Fung \& Lam, 2012; Lam, 2016; Lam, Cheung \& Chow, 2011a; Lam, Cheung \& Chow, 2011b; Lam \& Leung, 2016; Lam, Leung \& Chan, 2011; Lee, Lee \& Macfarlane, 2014). It improves health conditions on patients and is important to adolescents who grow rapidly during their puberty periods. Physical activity is an essential element to enhance their skeletal and muscular development. Therefore, it is of paramount important to promote physical activity (Li, Lam, Louie \& Li, 2012; Lau, Lam \& Leung, 2010; Lau, Lam \& Leung, 2011; Ho, Yiu \& Lam, 2016; Lam, 2010). Despite the well-known benefits, engaging in any kind of sports or physical activity are hindered by time constraints, lack of companion and interest (Burton \& Martens, 1986; Slater \& Tiggemann, 2010). Dropout of sport may reduce physical activity participation and thus affect the physical and psychological health of human beings (Lam et al., 2017a).

Prevention of dropout is a genuine challenge. It happens when young athletes are going to leave the college and they have to choose either becoming a full-time professional athlete or starting a new phrase of life in a non-sport related career (Cecic Erpic, Wylleman, \& Zupancic, 2004; Ryba, Stambulova, Ronkainen, Bundgaard, \& Selanne, 2015). They end their sport life because they can not further improve their sport performance (Burton \& Martens, 1986) or they have job-, health- or relationship-related reasons in the path of being a professional athlete (Maffulli, Longo, Gougoulias, Loppini, \& Denaro, 2010; Stambulova, Stephan, \& Japhag, 2007).

Studies suggested that sport performance, parents, peers, gender, age and injury (Lam et al., 2017b) were possible reasons for dropout of sport (Fraser-Thomas, Cote, \& Deakin, 2008; UllrichFrench \& Smith, 2009). Moreover, coach is regarded as the most important element in the engagement of sport, as he/she provides training program to enhance physical competence and also solves the psychological problems of athletes such as the motivation of sport, self-esteem, anxiety, relationship between teammates in training and competition (Baker, Cote, \& HAWES, 2000; Becker \& Solomon, 2005; Côté \& Gilbert, 2009; Gearity \& Murray, 2011; Rodrigues, Andrade, Graca, \& Mesquita, 2009).

The aim of this study was to identify the reason of dropout when the adolescent athletes were still at school, and it would provide further understanding on how previous dropout experience could possibly influence their perception of dropout in the future. With the results of this study, it would help to identify possible dropout risk factors and to implement specific programs to address these risk factors. We hypothesize that the dropout of sport would be mainly due to time constraints, lack of companion and interest, the influence of coaches, parents and peers, which are shown in the current literature. 


\section{Materials and Methods}

A convenient sampling was adopted without power calculation. There were 50 subjects $($ Male $=39$, Female $=11$ ) in this study. They were Chinese and aged 13-23 years. They were active athletes and trained at least twice per week. Half of the participants were the member of the Hong Kong Amateur Athletic Association (HKAAA), they were track and field athletes and usually trained at Tseung Kwan O Sport Ground and Wan Chai Sport Ground of Hong Kong after school hours. The remains were undergraduates majoring in Sport Coaching at the Hong Kong Institute of Vocational Education, Chai Wan Campus.

All participants were invited to fill in a two-page questionnaire on the potential reason of dropout in their current sport. It consisted of demographic information, dropout experience, training history and frequency, and perceived dropout reasons in following aspects: health, finance, parents, social value, personal aim, training, coach and teammates. These were closed questions, using a three-point Likert-type scale from 1 (Disagree), 2 (Neutral) to 3 (Agree).

A pilot study was conducted one week before the actual data collection. Five athletes were selected to fill in the questionnaire.

The results of pilot study did not include into the final analysis. Ethics approval was obtained from the Ethics Committee of Sheffield Hallam University, UK.

\section{Data collection and statistical analysis}

Data collection was conducted from 16 to 29 March 2016. Prior to the commencement of the questionnaire, questions were asked for screening of participants' eligibility. Verbal consent was further obtained for those who agreed to participate in this study. A field investigator passed the questionnaire to subject in person, before or after the training session. The questionnaire was selfexplanatory, but further explanation of questionnaire would be provided upon request. Questionnaire was anonymous; which was double-checked by the investigator once it was collected. A unique code was assigned to every completed questionnaire. The same procedure was applied to all subjects.

SPSS for the Window version 22 was used. Independent Samples T-Test, Pearson Chi-Square Test and Linear-by-Linear Chi-Square Test were used for statistical analysis. An explanatory alpha level of 0.05 was determined a priori to indicate statistical significant. Descriptive statistics including mean and standard errors of outcomes were reported.

\section{Results}

There were $44 \%$ of the subjects had previous dropout experience (Dropout Group) and $56 \%$ had no dropout experience (No Dropout Group). The basic characteristics are exhibited in Table 1.

\section{Coach and teammate-related reasons}

Coach and teammate-related reasons were the most important reasons of dropout by school athletes (Table 2). There was $64 \%$ of them selected coaching technique as the most essential reason. For dropout group, around $60 \%$ of them believed that character and training-related reasons of coach and teammates were major reasons of dropout. For no dropout group, half of them shared similar reasons, except the reasons of coaching style and attendance in teammates.

\section{Other reasons}

Reasons other than coach and teammate-related were also examined. The school athletes tended to perceive injury and no achievement as the possible reasons of dropout. In contrast, they disagreed that education level and expectation of parents and harsh training were possible reasons (Table 3). Loss of interest was an interesting variable, half of them (42\%) agreed as the possible reason of dropout, however, another half (42\%) disagreed.

\section{Perception differences on social value and lost focus}

Data was further compared between two groups. It was found that there was statistical significant difference $(\mathrm{P}<0.01)$ in the social between of these groups (Table 4). For athletes who had previous dropout experience, there were $31.8 \%, 22.7 \%$ and $45.5 \%$ of them

Table 1. Basic characteristics of subject $(n=50)$.

\begin{tabular}{lcc}
$\begin{array}{c}\text { Dropout Group } \\
(\mathrm{n}=22)\end{array}$ & $\begin{array}{c}\text { No Dropout Group } \\
(\mathrm{n}=28)\end{array}$ \\
Male & $18(81.8)$ & $21(75)$ \\
Female & $4(18.2)$ & $7(25)$ \\
\hline Age & $19.36 \pm 3.33$ & $18.25 \pm 3.23$ \\
Secondary Education & $4(18.2)$ & $11(39.3)$ \\
\hline Tertiary Education & $18(81.8)$ & $17(60.7)$ \\
\hline Variable of age is presented as mean \pm SD. Other variables are presented as count $(\%)$.
\end{tabular}

Table 2. Coach and teammate-related reasons of dropout.

\begin{tabular}{lccc} 
& $\begin{array}{c}\text { Dropout } \\
\text { Group } \\
(\mathbf{n = 2 2})\end{array}$ & $\begin{array}{c}\text { No Dropout } \\
\text { Group } \\
(\mathrm{n}=28)\end{array}$ & $\begin{array}{c}\text { All } \\
\text { participants } \\
(\mathrm{n}=50)\end{array}$ \\
$\begin{array}{l}\text { Coach } \\
\text { Technique }\end{array}$ & $15(68.2)$ & $17(60.7)$ & $32(64)$ \\
Style & $15(68.2)$ & $13(46.4)$ & $28(56)$ \\
Attitude & $13(59.1)$ & $15(53.6)$ & $28(56)$ \\
Care & $13(59.1)$ & $14(50)$ & $27(54)$ \\
Teammate & & & \\
Cohesion & $14(63.6)$ & $14(50)$ & $28(56)$ \\
Kindness & $13(59.1)$ & $15(53.6)$ & $28(56)$ \\
Training attitude & $13(59.1)$ & $14(50)$ & $27(54)$ \\
Attendance & $13(59.1)$ & $7(25)$ & $20(40)$ \\
\hline
\end{tabular}

Variables are presented as count (\%).

Table 3. Reasons that school athletes agreed or disagreed as dropout reasons.

\begin{tabular}{lccc} 
& $\begin{array}{c}\text { Dropout } \\
\text { Group } \\
(\mathrm{n}=22)\end{array}$ & $\begin{array}{c}\text { No Dropout } \\
\text { Group } \\
(\mathrm{n}=28)\end{array}$ & $\begin{array}{c}\text { All } \\
\text { participants } \\
(\mathrm{n}=50)\end{array}$ \\
$\begin{array}{l}\text { Agreed } \\
\text { Injury }\end{array}$ & $13(59.1)$ & $11(39.3)$ & $24(48)$ \\
$\quad$ No achievement & $12(54.3)$ & $12(42.9)$ & $24(48)$ \\
$\begin{array}{l}\text { Disagreed } \\
\quad \text { Parent's education }\end{array}$ & $16(72.7)$ & $18(64.3)$ & $34(68)$ \\
$\begin{array}{l}\text { Parent's expectation } \\
\text { Tough training }\end{array} \quad 14(40.9)$ & $16(57.1)$ & $25(50)$ \\
\hline
\end{tabular}

Variables are presented as count (\%) 
ranked Disagree, Neutral and Agree, respectively. For those who had no previous dropout experience, there were $64.3 \%, 25 \%$ and $10.7 \%$ of them ranked Disagree, Neutral and Agree, respectively. Furthermore, it was shown that their views on lost focus was statistical significant $(\mathrm{P}<0.05)$ (Table 5). For athletes who had previous dropout experience, there were $22.7 \%, 9.1 \%$ and $68.2 \%$ of them ranked Disagree, Neutral and Agree, respectively. For those who had no previous dropout experience, there were $35.7 \%, 39.3 \%$ and $25 \%$ of them ranked Disagree, Neutral and Agree, respectively.

\section{Discussion}

\section{Possible dropout reasons}

Most of the previous studies found that work-related reasons and other personal reasons (such as not interest, lazy and tired) were the common dropout reasons in general public (The Chinese University of Hong Kong, 2009). These studies were not specific, as the targeted participants were not regularly trained, the results could not apply to those trained regularly. This current study was a unique study which targeted active school athletes, and contributed to understand how they thought about their potential dropout reasons. The results of this study showed that the influence of coach and teammates played an important role for the reason for dropout.

\section{Coach}

Coach is a role model to his athletes. Coaching technique, coaching style, coach's attitude and coach's care were the essential elements for their dropout consideration. This results of the study agreed with previous studies that character of a coach and his coaching skills played an important role to his athletes (Blazar \& Kraft, 2015; Côté \& Gilbert, 2009; Koh, Mallett, \& Wang, 2009; Rodrigues et al., 2009). The duty of a coach is to improve sport performance of his athletes and it consists of both physical and psychological competence. The coach should have the knowledge of the effective training method to improve athletes' performance, and he should have positive attitude on problem solving (Côté \& Gilbert, 2009). He also should create and maintain a good relationship between each other, so fewer quarrels would have occurred (Becker, 2009). The coach should help his athletes develop their own practice, that was, a personalized training approach for the uniqueness of physique and sport position, or even character of each individual athletes (Nater \& Gillmore, 2008). The coach should communicate regularly with his athletes for better understanding on progression of training (Cushiona, Armourb, \& Jones, 2006).

\section{Teammate}

Teammate is another reason which affected possible dropout, this result agreed with that of previous studies (Patrick et al., 1999; Ullrich-French \& Smith, 2009; Weiss \& Weiss, 2004). When athletes accompanied with teammates, peers and friends, they had higher motivation to stay. However, if their teammates dropout, he may dropout. The character and training attitude of teammates influence each other (Dirks, 2000), they gained trust, respect and encouragement during competition and training. If the teammates communicate and cooperate effectively, it could increase the sport performance of the whole team. Team cohesion is especially critical in team sport, better team cohesion means better results. All of these factors could affect the potential dropout of school athletes.

\section{Parents}

It is no doubt that injury and no achievement were the possible dropout reasons, as previous studies had the same conclusion ( $\mathrm{P}$. Edouard, 2011; Pascal Edouard, Pruvost, Edouard, \& Morin, 2010; Scanlan \& Lewthwaite, 1986; Young, Pain, \& Pearce, 2007). However, it was found that parental influence was not regarded as a dropout reason for school athletes. It was different from the conclusion of a previous study which suggested parent could affect the possible decision of dropout sport in their children (Fraser-Thomas et al., 2008). The result of this study showed that half of the athletes $(50 \%)$ disagreed parent's expectation as a reason of dropout. The majority of the athletes $(68 \%)$ disagreed that parent's education level had any potential influence in dropout.

\section{Tough training}

It was usually found that tough training might cause athlete to dropout (Isoard-Gautheur, Guillet-Descas, \& Gustafsson, 2016; Salguero, Gonzalez-Boto, Tuero, \& Marquez, 2003). However, more than half of these school athletes (56\%) disagreed that tough training was one of the dropout reasons. It might be due to the fact that these athletes completely understood that they needed to train hard for success.

\section{Perception difference}

This was the first study to examine if any previous dropout experience would have influenced the perceived opinion of dropout. It would be highly valuable to know that the perceptions of dropout reason were different between these two groups; therefore, the preventive strategies of dropout should be implemented to these two groups differently.

\section{Social value}

The athletes were divided into two groups: those had dropout experience in previous sports and those did not have. Their opinions were further analyzed and compared, it helped to distinguish if there was any perception difference between them. The results showed that some perceptions presented differently between two groups; their social value and lost focus were significant different.

Table 4. Social value.

\begin{tabular}{|c|c|c|c|}
\hline & $\begin{array}{l}\text { Dropout } \\
\text { Group } \\
(n=22)\end{array}$ & $\begin{array}{l}\text { No Dropout } \\
\text { Group } \\
(n=28)\end{array}$ & $\begin{array}{c}\text { All } \\
\text { participants } \\
(n=50)\end{array}$ \\
\hline Disagree & $7(31.8)^{* *}$ & 18 (64.3) & $25(50)$ \\
\hline Neutral & $5(22.7)$ & $7(25)$ & $12(24)$ \\
\hline Agree & $10(45.5)$ & $3(10.7)$ & $13(26)$ \\
\hline
\end{tabular}

Table 5. Lost focus.

\begin{tabular}{|c|c|c|c|}
\hline & $\begin{array}{l}\text { Dropout } \\
\text { Group } \\
(\mathrm{n}=22)\end{array}$ & $\begin{array}{l}\text { No Dropout } \\
\text { Group } \\
(\mathrm{n}=28)\end{array}$ & $\begin{array}{c}\text { All } \\
\text { participants } \\
(\mathrm{n}=50)\end{array}$ \\
\hline Disagree & $5(22.7)^{*}$ & $10(35.7)$ & $15(30)$ \\
\hline Neutral & $2(9.1)$ & 11 (39.3) & $13(26)$ \\
\hline Agree & $15(68.2)$ & $7(25)$ & $22(44)$ \\
\hline
\end{tabular}


Almost half of the athletes who had dropout experience agreed that social value was a possible reason of dropout. Scanlan and Lewthwaite (1986) believed that social evaluation and recognition were two criteria for sport enjoyment. Athletes do not have adequate satisfactory to remain in the sport industry if their social evaluation and recognition were low. Boiché and Sarrazin (2009) suggested that social support was one of the social and cultural factors that could contribute to quantity and duration of physical participation. Brustad, Babkes and Smith (2001) also concluded that regular physical activity should link to social acceptance positively. This was further explained by Guilet et al. (2002), and they commented that social constraints could predict possible dropout in athletes. Athletes' perception of priorities in the activity might vary under different social conditions (Boiché \& Sarrazin, 2009). The results of this study showed that athletes with dropout experience agreed with the abovementioned studies but those with no experience disagreed. The possible explanation could be athletes with no dropout experience might be more independent from any external opinion, they believed themselves strongly, and thus had no dropout experience.

\section{Lost focus}

Lost focus was another possible dropout reason that there was significant different between two groups. Most of the athletes with dropout experience agreed that lost focus was a reason but only one fourth of athletes with no dropout experience agreed that. Kyllo and Lander (1995) said that goal setting was a reliable motivation, a higher standard of goal means a better effect of sport performance. However, when athletes lost their focus, they might felt frustrated in sport, leading to dropout. Lost focus seemed a dropout reason from their previous sport, in which they might dropout from the current sport due to the same reason. The possible explanation for this finding may due to the fact that athletes that had no previous dropout experience, they could have stronger determination with clear objectives. This explanation was similar to the belief by Bueno et al. that strong self-efficacy could resist threatening of failure and retain athlete in high motivation of sport (Bueno, Weinberg, Fernández-Castro, \& Capdevila, 2008).

\section{Limitations}

There are several limitations in this study. First, objective measures were not used which may affect the validity of the findings. Previous studies have shown the importance of having objective measures (Lee, Lam \& Deng, 2017b; Lee, Lam \& Lee, 2017; Lee, Macfarlane \& Cerin, 2013a; Lee, Macfarlane \& Cerin, $2013 b)$. Second, the contact time with coaches was not adjusted in the analyses, which may affect the findings (Lee, Lam \& Deng, 2017a). Sophisticated statistical analyses with adjustment of potential confounders (Lee, Tse \& Lee, 2016; Deng, Lee, Lam \& Lee, 2016) were not used due to the nature of data collected in this study. Moreover, imbalance of male and female participants and lack of power calculation of sample size were also among the limitations of this study.

\section{Conclusions}

Influence of coach and teammates were commonly found as factors of dropout. On the other hand, it was surprised to know that parent and training intensity were not related to a termination of sport participation. In order to eliminate the dropout rate for school athletes, a comprehensive training program, both physically and psychologically should be implemented and closely monitored. It would also be worthwhile to further investigate why the perception presented differently in two groups of athletes, that is, the group that had no previous dropout experiences seems to have stronger determination and clearer objectives, than those had dropout experience. Thus, psychological trainings should be implemented to all athletes from the beginning in order to address these elements.

\section{References}

Baker, J., Cote, J., \& Hawes, R. (2000). The relationship between coaching behaviours and sport anxiety in athletes. Journal of science and medicine in sport, 3(2), 110-119.

Becker, A.J. (2009). It's not what they do, it's how they do it: athlete experiences of great coaching. International Journal of Sports and Science \& Coaching, 4(1), 93-118.

Becker, A.J., \& Solomon, G.B. (2005). Expectancy information and coach effectiveness in intercollegiate basketball. The sport psychologist, 19(3), 251-266.

Blazar, D., \& Kraft, M.A. (2015). Exploring mechanisms of effective teacher coaching: a tale of two cohorts from a randomized experiment. Educational evaluation and policy analysis, 37(4), 542-566.

Boiché, J., \& Sarrazin, P. (2009). Proximal and distal factors associated with dropout versus maintained participation in organized sport. Journal of Sports Sciences and Medicine, 8, 9-16.

Brustad, R.J., Babkes, M.L., \& Smith, A.L. (2001). Youth in sport: psychological considerations. In Handbook of sport psychology (2nd ed.). New York: Wiley.

Bueno, J., Weinberg, R.S., Fernández-Castro, J., \& Capdevila, L. (2008). Emotional and motivational mechanisms mediating the influence of goal setting on endurance athletes' performance. Psychology of Sport and Exercise, 9(6), 786-799. doi: http://dx.doi.org/10.1016/j.psychsport.2007.11.003

Burton, D., \& Martens, R. (1986). Pinned by their own goals: an exploratory investigation into why kids drop out of wrestling. Journal of Sport Psychology, 8, 183-197.

Cecic Erpic, S., Wylleman, Z., \& Zupancic, M. (2004). The effect of athletic and non-athletic factors on the sports career termination process. Psychology of Sport and Exercise, 5, 45-59.

Côté, J., \& Gilbert, W. (2009). An integrative definition of coaching effectiveness and expertise. International journal of sports science \& coaching, 4(3), 307-323.

Cushiona, C.J., Armourb, K.M., \& Jones, R.L. (2006). Locating the coaching process in practice: models 'for' and 'of' coaching. Physical education and sport pedagogy, 11(1), 83-99.

Deng, Y., Lee, K.Y., Lam, M.H.S., \& Lee, P.H. (2016). Understanding sociobehavioral mitigators of depressive symptoms among US young adults. Behavioral Medicine, 42(4), 217-226.

Dirks, K. T. (2000). Trust in leadership and team performance: evidence from NCAA basketball. Journal of Applied Psychology, 85(6), 1004-1012.

Edouard, P. (2011). Frequency of dropouts in decathlon: an epidemiological retrospective study. Science \& Sports, 26(2), 97100. doi: http://dx.doi.org/10.1016/j.scispo.2010.11.002

Edouard, P., Pruvost, J., Edouard, J.L., \& Morin, J.B. (2010). Causes of dropouts in decathlon. A pilot study. Physical Therapy in Sport, 11(4), 133-135. doi: http://dx.doi.org/10.1016/j.ptsp.2010.07.004

Fraser-Thomas, J., Cote, J., \& Deakin, J. (2008). Understanding 
dropout and prolonged engagement in adolescent competitive sport. Journal of Sport and Exercise, 9, 645-662.

Fung, L., \& Lam, M.H.S. (2012). Effectiveness of a progressive stepping program on lower limb function in community dwelling older adults. Journal of Exercise Science \& Fitness, 10(1), 8-11.

Gearity, B.T., \& Murray, M.A. (2011). Athletes' experiences of the psychological effects of poor coaching. Psychology of Sport and Exercise, 12(3), 213-221.

Guillet, E., Sarrazin, P., Carpenter, P., Trouilloud, D., \& Cury, F. (2002). Predicting persistence or withdrawal in female handballers with social exchange theory. International Journal of Sports Psychology, 37, 92-104.

Ho, G., Yiu, E.Y.M., \& Lam, M.H.S. (2016). The Hong Kong games in the eyes of local sports and recreation students. The International Journal of the History of Sport, 33(11), 12091225 .

Isoard-Gautheur, S., Guillet-Descas, E., \& Gustafsson, H. (2016). Athlete burnout and the risk of dropout among young elite handball players. The sport psychologist, 30(2), 123-130.

Koh, K.T., Mallett, C., \& Wang, C.K.J. (2009). Examining the ecological validity of the coaching behavior scale (sports) for basketball. International Journal of Sports and Science \& Coaching, 4(2), 261-272.

Kyllo, L.B., \& Landers, D.M. (1995). Goal-setting in sport and exercise: A research synthesis to resolve the controversy. journal of Sport and Exercise Psychology, 17, 117-138.

Lam, M.H.S. (2010). Management evaluation of the healthy athlete program of 2007 Shanghai Special Olympics World Summer Games. Asian Journal of Physical Education \& Recreation, 16(2).

Lam, M.H.S. (2016). Exercise game exhilarates the elderly: a challenge to traditional training. Journal of Athletic Enhancement. doi: 10.4172/2324-9080.1000e109

Lam, M.H.S., Cheung, S.Y., \& Chow, B.C. (2011a). The effects of Tai-Chi-Soft-Ball training on physical functional health of Chinese older adult. Journal of Human Sport and Exercise, 6(3), 540-553.

Lam, M.H.S., Chow, B.C., Cheung, S.Y., Lee, K.Y., Li, W.H.C., Ho, E., Flint, S.W., Yang, L., \& Yung, N.K.F. (2017). A systematic review of recreation therapy for depression in older adults. Journal of Psychology \& Psychotherapy, 7(2), 2161-2487.

Lam, M.H.S., Cheung, S.Y., \& Chow, B.C. (2011b). Effects of Tai Chi soft ball training on health-related quality of life of older adults with functional limitations. Asian Journal of Gerontology \& Geriatrics, 6(2), 65-71.

Lam, M.H.S., \& Leung, A.Y.M. (2016). The effectiveness of health literacy oriented programs on physical activity behaviour in middle aged and older adults with type 2 diabetes: a systematic review. Health Psychology Research, 4(1).

Lam, M.H.S., Leung, A.Y.M., \& Chan, S.S.C. (2011). Psychological and cognitive determinants of the health literacy on soon to be aged and older adults: a systematic review. $i$ manager's Journal on Nursing, 1(2), 46.

Lam, M.H.S., Tung K., Man, D.P., Lee, K.Y., Lei, Y., Flint, S.W., Peake, R. (2017). Examining lower limb Injuries among male amateur soccer player. Journal of Yoga and Physical Therapy, 7: 264.

Lau, P.W., Lam, M.H.S., \& Leung, B.W. (2010). National identity and the Beijing Olympics: school children's responses in mainland China, Taiwan \& Hong Kong. Procedia-Social and Behavioral Sciences, 2(5), 6729-6738.

Lau, P.W., Lam, M.H.S., \& Leung, B.W. (2011). The Beijing
Olympics and expressions of national identity in China, Taiwan and Hong Kong. The Olympics in East Asia: Nationalism, Regionalism, and Globalism on the Center Stage of World Sports, 147.

Lee, K.Y., Lam, M.H.S., \& Deng, Y. (2017a). Interventions for anxiety and depression in conflict-affected areas. Jama, 317(13), 1376-1376.

Lee, K.Y., Lam, M.H.S., \& Deng, Y. (2017b). Measuring postconcussive activity levels of patients: step count or activity intensity? JAMA pediatrics. 171,493-494.

Lee, K.Y., Lam, M.H.S., \& Lee, P.H. (2017). Distance from home to the nearest tobacco outlet may not reflect the true accessibility. JAMA Internal Medicine, 177(2), 287-287.

Lee, K.Y., Lee, P.H., \& Macfarlane, D. (2014). Associations between moderate-to-vigorous physical activity and neighbourhood recreational facilities: the features of the facilities matter. International journal of environmental research and public health, 11(12), 12594-12610.

Lee, K.Y., Macfarlane, D.J., \& Cerin, E. (2013). Objective evaluation of recreational facilities: Development and reliability of the recreational facility audit tool. Journal of Park and Recreation Administration, 31(4), 92-109.

Lee, K.Y., Macfarlane, D.J., \& Cerin, E. (2013). Comparison of three models of actigraph accelerometers during free living and controlled laboratory conditions. European journal of sport science, 13(3), 332-339.

Lee, P.H., Tse, A.C., \& Lee, K.Y. (2016). A new statistical model for the Day Reconstruction method. International journal of methods in psychiatric research. doi: 10.1002/mpr.1547.

Li, E.-J., Lam, M.H.S., Louie, L.H.T., \& Li, S.S.S. (2012). An analysis on history and cultural background of Chinese Tai Chi Soft Ball. Asian Journal of Physical Education \& Recreation, $18(1)$.

Maffulli, N., Longo, U.G., Gougoulias, N., Loppini, M., \& Denaro, V. (2010). Long-term health outcomes of youth sports injuries. British Journal of Sports Medicine, 44(1), 21-25. doi:10.1136/bjsm.2009.069526

Nater, S., \& Gillmore, R. (2008). You haven't taught until they have learned: John Wooden's teaching principles and practices. Fitness Informtion Technology, 17(1), 102-107.

Patrick, H., Ryan, A.M., Alfeld-Liro, C., Fredricks, J.A., Hruda, L.Z., \& Eccles, J.S. (1999). Adolescents' Commitment to developing talent: the role of peers in continuing motivation for sports and the arts. Journal of Youth and Adolescence, 28(6), 741-763. doi:10.1023/a:1021643718575

Rodrigues, J., Andrade, R., Graca, A., \& Mesquita, I. (2009). Importance awarded to knowledge for coaching and self-perception of competence manifested by Portuguese basketball coaches. Revista de psicología del deporte, 18(3), 451-455.

Ryba, T.V., Stambulova, N.B., Ronkainen, N.J., Bundgaard, J., \& Selanne, H. (2015). Dual career pathways of transnational athletes. Psychology of Sport and Exercise, 21, 125-134.

Salguero, A., Gonzalez-Boto, R., Tuero, C., \& Marquez, S. (2003). Identification of dropout reasons in young competitive swimmers. Journal of Sports Medicine and Physical Fitness, 43(4), 530-534.

Scanlan, T.K., \& Lewthwaite, R. (1986). Social psychological aspects of competition for male youth sport participants: IV. Predicitors of enjoyment. Journal of Sport Psychology, 8(1), 25-35.

Slater, A., \& Tiggemann, M. (2010). "Uncool to do sport": a focus group study of adolescent girls' reasons for withdrawing from physical activity. Psychology of Sport and Exercise, 11, 619- 
626.

Stambulova, N.B., Stephan, Y., \& Japhag, U. (2007). Athletic retirement: a cross-national comparison of elite French and Swedish athletes. Psychology of Sport and Exercise, 8, 101118.

The Chinese University of Hong Kong. (2009). Consultancy study on sport for all-participation patterns of Hong Kong people in physical activities. Hong Kong: Hong Kong Government.

Ullrich-French, S., \& Smith, A. L. (2009). Social and motivational predictors of continued youth sport participation. Psychology of Sport and Exercise, 10(1), 87-95. doi: http://dx.doi.org/10.1016/j.psychsport.2008.06.007

Weiss, W.M., \& Weiss, M.R. (2004). Exploring development difference in sport commitment Journal of Sport and Exercise Psychology, S197.

Young, J.A., Pain, M.D., \& Pearce, A.J. (2007). Experiences of Australian professional female tennis players returning to competition from injury. British Journal of Sports Medicine, 41(11), 806-811. doi: 10.1136/bjsm.2007.036541 